\title{
Avaliação financeira e desempenho produtivo de Sistemas Agroflorestais
}

\section{Agroecológicos}

\author{
Financial evaluation and productive performance of agroforestry agroecology systems \\ Evaluación financiera y desempeño productivo de sistemas agroforestales agroecologico
}

Recebido: 18/04/2021 | Revisado: 23/04/2021 | Aceito: 25/04/2021 | Publicado: 09/05/2021

\author{
Martin Ewert \\ ORCID: https://orcid.org/0000-0003-4119-086X \\ Universidade Federal de Santa Catarina, Brasil \\ E-mail: nitram.ewert@gmail.com \\ Marcelo Francia Arco-Verde \\ ORCID: https://orcid.org/0000-0001-6545-9961 \\ Embrapa Florestas, Brasil \\ E-mail: marcelo.arco-verde@embrapa.br \\ Viviane Helena Palma \\ ORCID: https://orcid.org/0000-0003-4178-6225 \\ Universidade Federal do Paraná, Brasil \\ E-mail: Viviane-palma@outlook.com \\ Daniele Cristina da Silva Kazama \\ ORCID: https://orcid.org/0000-0002-7849-6064 \\ Universidade Federal de Santa Catarina, Brasi \\ E-mail: danielekazama@yahoo.com.br
}

\begin{abstract}
Resumo
Os Sistemas Agroflorestais (SAFs) surgem para potencializar a produtividade dos agroecossistemas e melhorar os ganhos financeiros da agricultura familiar. Questiona-se neste estudo a efetividade do uso de SAFs ampliarem a produtividade e o rendimento financeiro de pequenas áreas. Assim, o objetivo do estudo é avaliar o desempenho produtivo, a demanda de mão de obra e a eficiência financeira dos SAFs. A metodologia baseou-se em um Estudo de Caso, onde durante o período de seis meses foram coletadas informações por meio de entrevistas semiestruturadas, bem como foi acompanhado o cotidiano de três agricultores que estão inseridos no contexto do assentamento Contestado, no município da Lapa, Paraná. Para realizar o prognóstico da análise financeira foi utilizado a planilha AmazonSAF 8.1. No modelo otimizado, dos três agricultores acompanhados, o SAF-3 apresentou o melhor desempenho produtivo financeiro, ultrapassando 17 ton/0.5ha/ano de alimento, que corresponde a um VPL de R\$ 339,123.40 mil reais durante o período analisado com garantia de venda pelo Plano Nacional de Alimentação Escolar (PNAE). A demanda de mão de obra, em todos os SAFs, se concentra no cultivo das espécies de ciclo curto, atingindo mais de 200 diárias por ano. Conclui-se que os indicadores financeiros oficiais demonstram viabilidade financeira para os três SAFs. Mas o fluxo de caixa não demonstra regularidade da rentabilidade a partir do oitavo ou nono ano até o 15, pois as receitas das hortaliças foram tão altas nos primeiros anos de cultivo que conseguiram manter os indicadores financeiros positivos para todo período.
\end{abstract}

Palavras-chave: AmazonSAF 8.1; Eficiência financeira; Planejamento; Rentabilidade.

\begin{abstract}
Agroforestry Systems (AFS) appears to enhance the productivity of agro-ecosystems and improve the financial gains of family farming. It is questioned in this study the effectiveness of the use of SAFs to increase the productivity and the financial income of small areas. Thus, the objective of the study is to evaluate the productive performance, the labor demand and the financial efficiency of the SAFs. The methodology was based on a case study, where during the period of six months information was collected through semi-structured interviews, as well as the daily routine of three farmers who are inserted in the context of the Contested Settlement, in the municipality of Lapa, Paraná. To perform the prognosis of the financial analysis, the AmazonSAF 8.1 spreadsheet was used. On the optimized model, from three accompanied farmers, the SAF-3 presented the best financial productive performance, exceeding 17 tons / 0.5 ha / year of food, which corresponds to a NPV of R \$339,123.40 during the analyzed period with guaranteed sale by the National School Feeding Plan (PNAE). The demand for labor, in all SAFs, is concentrated in the cultivation of short-cycle species, reaching more than 200 daily working per year. It is concluded official financial indicators demonstrate financial viability for the three SAFs. But the cash flow does not demonstrate regular profitability from the eighth or ninth year until the $15^{\text {th }}$, because vegetable revenues were so high in the first years of cultivation that they managed to maintain positive financial indicators for the entire period.
\end{abstract}

Keywords: AmazonSAF 8.1; Financial Efficiency; Planning; Profitability. 


\begin{abstract}
Resumen
Los sistemas agroforestales (SAF) parecen mejorar la productividad de los agroecosistemas y mejorar las ganancias financieras de la agricultura familiar. En este estudio se cuestiona la efectividad del uso de SAF para incrementar la productividad y los ingresos financieros en áreas pequeñas. Así, el objetivo del estudio es evaluar el desempeño productivo, la demanda de mano de obra y la eficiencia financiera de las SAF. La metodología se basó en un Estudio de Caso, donde durante el período de seis meses se recopiló información a través de entrevistas semiestructuradas, así como la rutina diaria de tres agricultores que se insertan en el contexto del asentamiento Contestado, en el municipio de Lapa, Paraná. Para realizar el pronóstico del análisis financiero se utilizó la hoja de cálculo AmazonSAF 8.1. En modelo optimizado, de los tres agricultores monitoreados, SAF-3 mostró el mejor desempeño productivo financiero, superando las 17ton / 0.5ha / año de alimentos, lo que corresponde a un VAN de R \$339.123,40 mil durante el período analizado con venta garantizada Escuela Nacional Plan de alimentación (PNAE). La demanda de mano de obra, en todas las SAF, se concentra en cultivo de especies de ciclo corto, llegando a más de 200 diarios por año. Se concluye que los indicadores financieros oficiales demuestran la viabilidad financiera de los tres SAF. Pero flujo de caja no muestra una rentabilidad regular desde el octavo o noveno año hasta el 15, ya que los ingresos por hortalizas fueron tan altos en los primeros años de cultivo que lograron mantener indicadores financieros positivos durante todo el período.
\end{abstract}

Palabras clave: AmazonSAF 8.1; Eficiencia financiera; Planificación; Rentabilidad.

\title{
1. Introdução
}

Nas últimas décadas, houve um aumento populacional significativo nas cidades, sendo que mais de $80 \%$ da população brasileira atualmente vive em áreas urbanas. Para a maioria das pessoas que permanecem no campo, superar a pobreza é um dos principais obstáculos, entre outras tantas dificuldades. Segundo indica o censo agropecuário do IBGE (2017), 8,5\% da população rural brasileira está abaixo da linha da pobreza com uma renda menor que $\mathrm{R} \$ 140,00$ reais mensais. Soma-se a este cenário o atual modelo hegemônico de agricultura empresarial, que necessita de grandes áreas para produção em escala e detém a maior parte da concentração de terras e riqueza econômica, sendo que 1\% dos proprietários de terra com mais de 1.000 hectares possuem $45,1 \%$ da área agricultável brasileira e que, visto sob essa ótica, reflete a expressão máxima da desigualdade social e sua relação com a pobreza no meio rural. Neste modelo, considera-se que o aumento da produtividade está relacionado a inclusão de insumos artificiais e técnicas degradantes aos agroecossistemas e a saúde humana (Primavesi, 1997; Camargo, et al., 2002; Caporal \& Costabeber, 2004; IICA, 2013). Além disso, observa-se no território nacional, o crescimento das Plantações Industriais de Árvores (PIAS), consideradas grandes plantações em monoculturas de manejo intensivo, formadas, em sua maioria por árvores exóticas. Do mesmo modo que a agricultura empresarial, tais plantações estão atreladas a impactos ambientais e sociais negativos, como o acesso a posse da terra, violação dos direitos humanos e o aumento do desmatamento de florestas nativas para o uso do cultivo dessas plantações (Overbeek, et al., 2012). No outro extremo, a agricultura familiar, que representa 89,3\% dos proprietários de terra - com áreas menores de 100 hectares -, utilizam 20\% do território agrícola nacional e produzem grande parte dos alimentos consumidos no País (Camargo et al., 2002; IBGE, 2017).

Este cenário reflete a vasta heterogeneidade no meio rural e a complexa análise da desigualdade social, especialmente as distintas questões relacionadas a avaliação sobre a pobreza no campo. Este fenômeno multidimensional é descrito na Abordagem das Capacitações, de Amartya Sen (2000), por meio de uma nova visão de justiça social. Conforme essa perspectiva, a condição de pobreza não deve se limitar à desigualdade de renda ou riqueza, mas pobre também é aquele ser humano que não tem condições de desenvolver suas capacidades. Esse enfoque considera que para as crianças, mulheres e homens desenvolverem suas capacidades, é necessário ter oportunidades para realizar situações desejáveis, entre elas acesso a saúde, educação e lazer. Outra ênfase é dada na liberdade de optar por um tipo de vida em comparação ao outro (Sen, 2000). Em uma análise distinta, ao se aproximar do contexto da vida no campo, percebe-se que na esmagadora maioria das vezes, não falta comida na mesa. Embora a renda possa ser relativamente baixa, a pobreza está relacionada ao acesso às realizações, levando em conta a melhoria da qualidade de vida, uma boa moradia, saúde, bem viver e educação. 
Diante desse contexto, os SAFs têm sido apresentados na literatura como uma das respostas para os desafios que a humanidade enfrenta. Entre as ambições de quem desenvolve projetos de SAFs, supõem-se que habita o objetivo de superar a pobreza no campo, gerar justiça social, ampliar sua renda por meio da produtividade, além de todos os aspectos ecológicos que esse sistema garante para manutenção da vida no planeta (Nair, 1997; Paludo \& Costabeber, 2012; Silva, 2013; Ewert, 2016). De fato, pouco se sabe se os SAFs são efetivamente capazes de elevar a renda, promover o bem viver de forma a oportunizar melhores condições de vida para agricultura familiar. Nesse sentido, há poucas informações quantitativas sobre sua eficiência produtiva e a rentabilidade necessária na agricultura contemporânea.

Considera-se que, para superar a pobreza no campo é preciso incentivar, por meio de pesquisas multidisciplinares, modelos que estimulem o uso regenerativo do solo, de modo a conservar a biodiversidade dos ecossistemas e, sobretudo, defender a justiça social daqueles que representam a agricultura familiar. Assim, este artigo teve como objetivo principal avaliar o desempenho produtivo, a demanda de mão de obra e a eficiência financeira de sistemas agroflorestais agroecológicos em três unidades produtivas do assentamento Contestado. As perguntas que nortearam a pesquisa foram: Qual a demanda de mão de obra necessária para desenvolver um projeto de SAF? Os sistemas agroflorestais agroecológicos estão sendo efetivamente rentáveis no longo prazo?

O que a pesquisa pretende mensurar são os gradientes de curto, médio e longo prazo de três unidades de produção agroflorestal no assentamento Contestado e revelar os diferentes estágios de evolução produtiva, financeira e mão de obra.

\section{Metodologia}

O local de desenvolvimento do estudo foi o assentamento Contestado, formado por mais de 150 famílias, no município da Lapa, localizado no estado do Paraná, Brasil, em uma altitude de 908 metros, entre o primeiro e segundo planalto paranaense, nos Campos Gerais. Segundo a classificação de Köppen, o clima da região é Cfb - temperado com verão ameno e chuvas uniformes distribuídas ao longo do ano, com geadas severas e frequentes. O mês mais frio apresenta temperatura média inferior a $17^{\circ} \mathrm{C}$ (mesotérmico), no mês mais quente a temperatura média é inferior a $22^{\circ} \mathrm{C}$, com 2.085 horas de sol e 280 horas de frio por ano com temperatura abaixo $13{ }^{\circ} \mathrm{C}$ e sem estação seca definida, e a precipitação média anual é de $1320 \mathrm{~mm}$ (Bigarella, et al., 1997; Wrege, 2012).

A pesquisa foi desenvolvida a partir dessa realidade por meio de um Estudo de Caso, para combinar de forma complementar objetivo qualitativos e quantitativos (Yin, 2015; Pereira, 2018), por meio da racionalidade ambiental como fio condutor para a valorização e reconhecimento dos atores, práticas e falas que consolidam processos alternativos de desenvolvimento rural (Sousa-Santos, 2009; Leff, 2011). A matriz metodológica ocorreu por meio da gestão inclusiva no período de janeiro e fevereiro de 2018, em diversas capacitações envolvendo lideranças do assentamento, técnicos da Embrapa Florestas, pós-graduandos da Universidade Federal de Santa Catarina (UFSC) e da Universidade Federal do Paraná (UFPR), estudantes da Escola Latino-Americana de Agroecologia (ELAA) e 19 agricultores que participaram ativamente na avaliação do processo de implantação dos SAFs. Estes 19 agricultores são parte do grupo de 36 famílias que implantaram em seus lotes SAFs no ano de 2011. As capacitações foram registradas por meio de gravações, documentadas em atas de reunião e utilizadas nesta pesquisa como fonte secundária de informação, bem como parâmetro de validação dos resultados da pesquisa. Foram construídos, de modo colaborativo, ajustes e melhorias dos SAFs implantados pelos agricultores em 2011. Estes ajustes e melhorias ocorreram com base na visão dos técnicos em consonância com a visão dos agricultores a partir das expressões, percepções e posicionamentos de todos os participantes. Posteriormente sua interpretação foi discutida conjuntamente. Em seguida foi elaborado um novo modelo de SAF que ocorreu por meio de metodologia participativa. O objetivo dessa dinâmica foi maximizar a produtividade ao compor um arranjo adequado de espécies a partir de um levantamento de todas as espécies cultivadas no assentamento e aquelas que os agricultores gostariam de cultivar no novo modelo. Essas espécies foram divididas 
em categorias, sendo elas: anuais; semi-perenes; perenes e respectivas subcategorias as quais cumprem a função de adubadeiras.

No período de fevereiro a julho foram acompanhados três agricultores agroflorestais agroecológicos (SAF-1, SAF-2 e SAF-3) localizados na Figura 1, associadas a Cooperativa Terra Livre, que também contribuíram com o grupo dos 19 agricultores que fizeram parte das capacitações iniciais. Os três sistemas avaliados foram escolhidos pelos próprios agricultores durante as capacitações, sendo considerados SAFs de melhor eficiência produtiva no Assentamento. Durante este período, aplicou-se um questionário semiestruturado com perguntas abertas e fechadas para validação das informações e coeficientes técnicos de produtividade, tempo de trabalho, custos e receitas, comercialização, dificuldades enfrentadas, dentre outros aspectos discutidos nas capacitações. As informações foram registradas por meio de um formulário de roteiro, gravações e registros fotográficos. Essas informações foram computadas de forma qualitativa e quantitativa para compreender a realidade pesquisada.

Figura 1: Localização geográfica dos sistemas agroflorestais no assentamento Contestado.

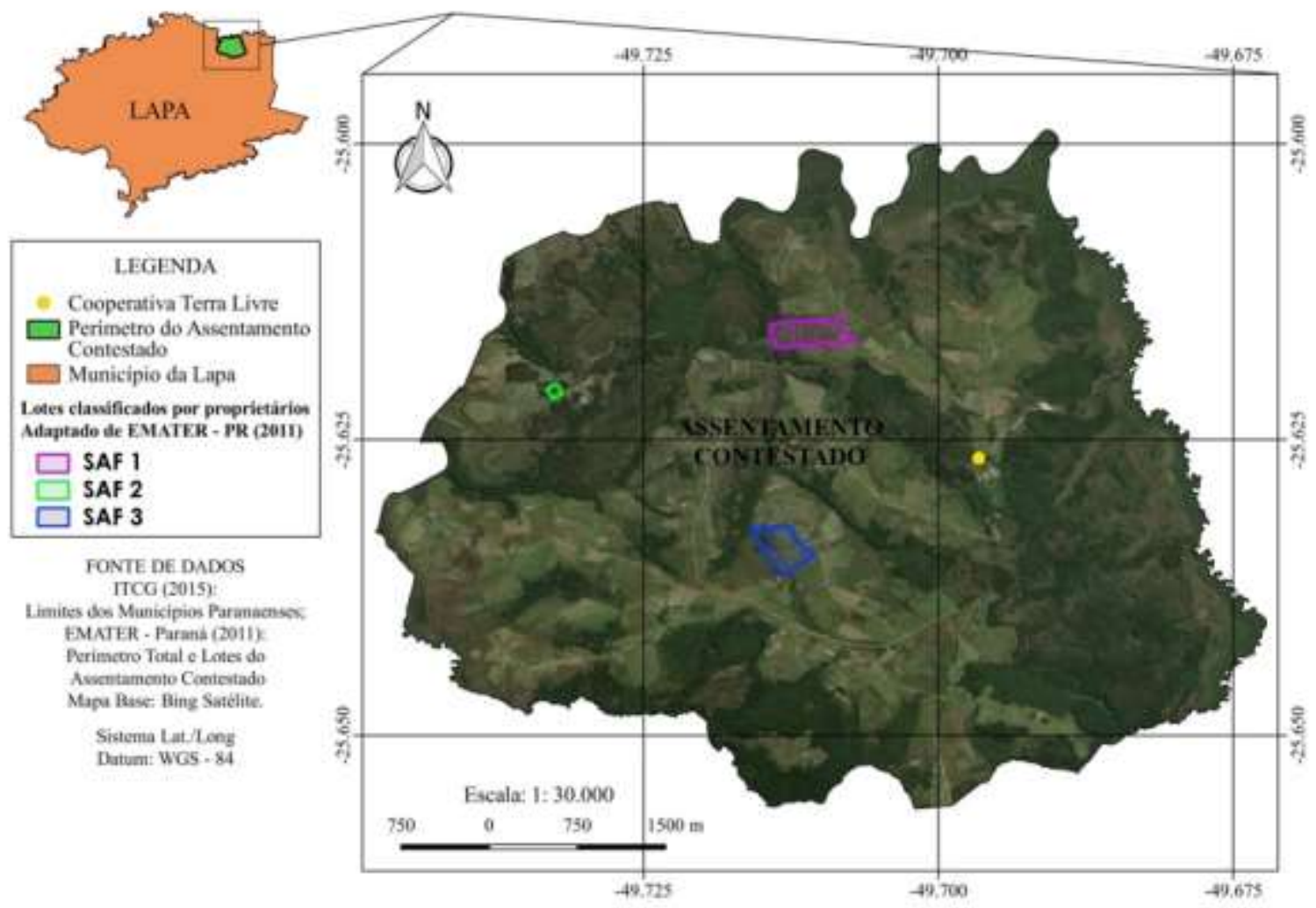

Fonte: Autores (2018).

A Tabela 1 apresenta algumas características dos sistemas agroflorestais analisados que foram utilizadas para compreender a heterogeneidade dos sistemas. Também se ressalta o tamanho da área disponível de cada lote, sendo o maior de 15.3 hectares e o menor de apenas 1.32 hectares. Essa informação serviu como estratégia para refletir juntamente com os resultados da pesquisa sobre a capacidade de ampliar as áreas de produção agroflorestal e sobre a disponibilidade da mão de obra para realizar as atividades. É importante destacar que o SAF-3 é o modelo otimizado, criado com o grupo e implantado com algumas adaptações - pelo agricultor no ano de 2018. Os outros modelos foram implantados respectivamente em 2012 e 2013, e avaliados a partir deste período. Assim o período de prognose dos modelos analisados nesta pesquisa foi de 15 anos e 
as áreas consideradas para criar os resultados foram de aproximadamente 0.5 hectares. A compreensão do tempo de 15 anos foi: curto para 05 anos; médio para 10 anos; e no longo prazo para 15 anos.

Tabela 1: Características dos sistemas agroflorestais analisados no assentamento Contestado.

\begin{tabular}{lcccccc}
\hline Modelo & $\begin{array}{c}\text { Área total } \\
\text { do lote }\end{array}$ & $\begin{array}{c}\text { Ano de implantação do } \\
\text { SAF avaliado }\end{array}$ & $\begin{array}{c}\text { Mão de Obra } \\
\text { disponível }\end{array}$ & $\begin{array}{c}\text { Dedicação do tempo } \\
\text { de trabalho }\end{array}$ & $\begin{array}{c}\mathbf{N}^{\circ} \text { total de } \\
\text { espécies }\end{array}$ & $\begin{array}{c}\mathbf{N}^{\circ} \text { total de } \\
\text { espécies perenes }\end{array}$ \\
\hline SAF-1 & 15.3 ha & 2012 & 2 & Exclusiva & 23 & 11 \\
\hline SAF-2 & 1.32 ha & 2013 & 2 & Exclusiva & 20 & 2 \\
\hline SAF-3 & 12.8 ha & 2018 & 3 & Exclusiva & 15 & 4 \\
\hline
\end{tabular}

Fonte: Autores (2019).

O método para gerar os resultados da análise financeira foi a planilha AmazonSAF 8.1 criado pela Embrapa (ArcoVerde \& Amaro, 2014). Os coeficientes técnicos de tempo de trabalho para cada atividade, produtividade das espécies, sazonalidades, preço de venda dos produtos determinados para criar a análise financeira foram validados pelos próprios agricultores em reuniões organizadas pelos pesquisadores responsáveis por este trabalho (Palma, et al., 2020). Os indicadores financeiros utilizados foram: valor presente líquido (VPL), Equação (Eq.1); relação benefício-custo (B/C) (Eq.2); e tempo de recuperação do investimento, também conhecido como Payback), citados por Arco-Verde \& Amaro (2014). Além disso, a planilha possibilita análise fina de nuances do fluxo de caixa e de demanda de mão de obra por período do projeto, bem como custos e receitas para cada produto.

$$
V P L=-I+\sum_{j=1}^{n} \frac{R_{j}-C_{j}}{(1+i)^{j}}=0
$$

Onde: $\mathrm{Rj}$ = receitas no período $\mathrm{j} ; \mathrm{Cj}=$ custos no período $\mathrm{j} ; \mathrm{i}=$ taxa de desconto (juros); $\mathrm{j}$ = período de ocorrência de Rje $\mathrm{Cj} ; \mathrm{n}$ = duração do projeto, em número de períodos; $\mathrm{I}$ = investimento inicial

$$
B / C=\frac{\sum_{j=0}^{n} R_{j}(1+i)^{j}}{\sum_{j=0}^{n} C j(1+i)^{j}}
$$

Onde: $\mathrm{Rj}=$ receitas no período $\mathrm{j} ; \mathrm{Cj}=$ custos no período $\mathrm{j} ; \mathrm{i}=$ taxa de desconto (juros); $\mathrm{j}=$ período de ocorrência de $\mathrm{Rje}$ $\mathrm{Cj} ; \mathrm{n}=$ duração do projeto, em número de períodos.

Além disso, foi considerado a mão de obra de apenas uma pessoa no valor da diária estabelecido na região em R \$ 60,00 reais para 8 horas de trabalho. Esse é o valor que foi descontado na análise financeira por dia de trabalho dos agricultores em seus sistemas, exceto pelo SAF-3, onde o agricultor estabeleceu o pagamento no valor da mão de obra em R\$ 80,00 reais. É importante mencionar ainda que o que assegura os resultados financeiros por espécie é a comercialização dos produtos com valor justo de mercado oferecido pela política pública do Plano Nacional de Alimentação Escolar (PNAE). Assim, a base dos cálculos do preço de venda da grande maioria dos produtos comercializados pelos agricultores para análise desses resultados foi a tabela do PNAE. Embora exista um desconto de 30\% desse valor que é arrecadado pela Cooperativa Terra Livre para manter a estrutura administrativa, observou-se que o ganho é superior ao preço de venda do mercado convencional.

Todas as espécies alimentícias cultivadas nos três modelos de SAF são eventualmente utilizadas para o autoconsumo das famílias. Então, considerou-se como a principal função apenas a comercialização e as plantas utilizadas como adubadoras (Tabela 2). Vale salientar que a densidade das espécies anuais é multiplicada pelo número de vezes que será cultivado por ano, 
mas também é multiplicado pelo número de canteiros cultivados de uma determinada planta. Para realizar os cálculos do AmazonSAF 8.1 é necessário ter a produtividade relativa de cada planta e descontar a perda de produtividade. Essa porcentagem de perda ocorre naturalmente por diversas razões, como fatores climáticos, manejo e colheita realizados de forma incorreta, qualidade e saúde do solo e eventuais doenças causadas por excesso ou falta de nutrientes, água e luz.

Tabela 2: Espécies, função principal e densidade dos sistemas agroflorestais no assentamento Contestado.

\begin{tabular}{|c|c|c|c|c|c|}
\hline \multicolumn{2}{|c|}{ Plantas de ciclo curto } & \multirow{2}{*}{$\begin{array}{l}\text { Principal } \\
\text { função }\end{array}$} & \multicolumn{3}{|c|}{ Densidade por canteiro } \\
\hline Nomes científicos & Nomes populares & & SAF-1 & SAF-2 & SAF-3 \\
\hline Cucúrbita máxima & Abóbora Moranga & Venda & - & 100 & - \\
\hline Cucurbita pepo & Abobrinha & Venda & 400 & 400 & 336 \\
\hline Curcuma longa $\mathrm{L}$. & Açafrão & Venda & - & 100 & - \\
\hline Beta vulgaris subsp. vulgaris & Acelga & Venda & - & - & 504 \\
\hline Lactuca sativa $\mathbf{L}$ & Alface & Venda & 1000 & 1000 & 504 \\
\hline Allium sativum $L$. & Alho & Venda & - & 8000 & - \\
\hline Cichorium intybus $\mathbf{L}$. & Almeirão & Venda & 500 & 500 & 504 \\
\hline Ipomoea batatas (L.) Lam. L. & Batata doce & Venda & - & 500 & - \\
\hline Solanum tuberosum 'Doré' & Batata Inglesa & Venda & 500 & - & - \\
\hline Beta vulgaris $\mathrm{L}$ & Beterraba & Venda & 1000 & 1000 & 1344 \\
\hline Brassica oleracea var. italica Plenck & Brócolis & Venda & - & 400 & 336 \\
\hline Pennisetum purpureum & Capim Elefante & Adubadora & 100 & - & - \\
\hline Allium cepa $\mathrm{L}$. & Cebola & Venda & 1000 & - & - \\
\hline Allium schoenoprasum $\mathbf{L}$. & Cebolinha & Venda & - & 8000 & - \\
\hline Daucus carota $\mathbf{L}$. & Cenoura & Venda & 2500 & & - \\
\hline Brassica oleracea var. acephala DC. & Couve & Venda & - & 400 & - \\
\hline Brassica oleracea var. botrytis L. & Couve-flor & Venda & 400 & - & 336 \\
\hline Cichorium endivia $\mathrm{L}$. & Escarola & Venda & 1000 & 1000 & - \\
\hline Colocasia esculenta (L.) Schott & Inhame & Venda & - & 100 & 84 \\
\hline Manihot esculenta Crantz & Mandioca & Venda & - & 100 & - \\
\hline Brassica oleracea var. capitata $L$. & Repolho & Venda & 400 & 400 & 336 \\
\hline Eruca sativa Mill. & Rúcula & Venda & - & - & 504 \\
\hline Solanum lycopersicum var. cerasiforme & Tomate Cereja & Venda & - & 400 & - \\
\hline \multicolumn{2}{|c|}{ Plantas semi-perenes e perenes } & \multicolumn{4}{|c|}{ Densidade total } \\
\hline Nomes científicos & Nomes populares & função & SAF-1 & SAF-2 & SAF-3 \\
\hline Psidium cattleyanum & Araçá & venda & 60 & - & - \\
\hline Musa spp. & Banana & Adubadora & - & 540 & 560 \\
\hline Diospyros kaki & Caqui & Venda & - & - & 28 \\
\hline Citrus spp. & Citros & venda & 96 & 132 & 45 \\
\hline Eucalyptus spp. & Eucalipto & Mourão & 306 & 270 & - \\
\hline Ficus carica $\mathbf{L}$. & Figo & Venda & 32 & 132 & - \\
\hline Acca sellowiana (O. Berg) Burret & Goiaba serrana & Venda & 32 & - & - \\
\hline Campomanesia pubescens & Gabiroba & Venda & 32 & - & - \\
\hline Malus domestica (Suckow) Borkh. & Maçã & Venda & 48 & - & - \\
\hline Cydonia oblonga Mill. & Marmelo & Venda & 44 & - & - \\
\hline Prunus persica var. nucipersica & Nectarina & Venda & 32 & - & - \\
\hline Carya illinoinensis & Nogueira Pecan & Venda & - & - & 16 \\
\hline Pyrus communis $\mathbf{L}$. & Pera & Venda & 32 & - & - \\
\hline Prunus persica (L.) Batsch & Pêsssego & Venda & 32 & - & - \\
\hline Eugenia uniflora $\mathbf{L}$ & Ponkan & Venda & - & - & 45 \\
\hline
\end{tabular}




\section{Resultados e Discussão}

\subsection{Demanda de mão de obra necessária para desenvolver um projeto de SAF}

A mão de obra é considerada um custo de oportunidade, sendo um dos aspectos mais importantes em pequenas unidades familiares de produção de alimento (Thompson \& George, 2009; Arco-Verde \& Amaro, 2018). A análise da mão de obra e o tempo de trabalho necessário para realizar cada atividade que envolve o preparo da área, plantio, manejo e colheita do sistema, são aspectos utilizados para observar como e onde o agricultor está investindo seu tempo. Muitas vezes o agricultor não percebe o valor da sua mão de obra e tão pouco, as possibilidades de otimizar seu tempo de trabalho (Santos \& Paiva, 2002) e com isso, perde oportunidade de melhorar significativamente seu rendimento financeiro. Ao refletir sobre a análise de mão de obra, o primeiro pensamento dos agricultores foi sobre sua capacidade de ampliar as áreas de produção. Observou-se nesta pesquisa que o maior desejo é criar um cenário de produção em escalas maiores. Essa tendência surge e se justifica possivelmente a partir do interesse de copiar modelos de monocultura, que são altamente mecanizados e fazem uso de tecnologias de ponta (Paludo \& Costabeber, 2012).

Figura 2: Demanda de mão de obra do SAF-1.

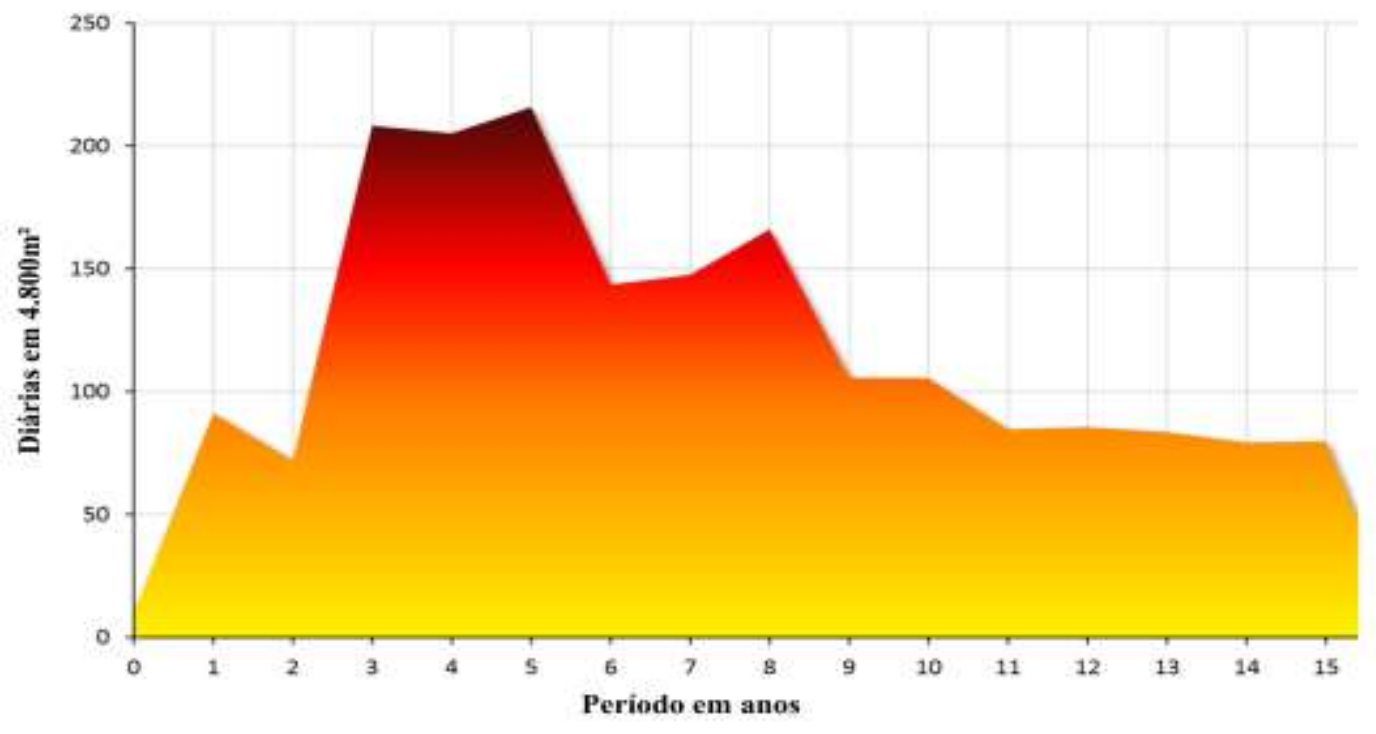

Fonte: Autores (2020).

O SAF-1, apresentado na Figura 2, possui a maior diversidade de espécies cultivadas no sistema ao longo de 15 anos, especialmente espécies perenes. Por outro lado, é o sistema com a menor mão de obra nos primeiros 5 anos e ao mesmo tempo, possui a partir do $10^{\circ}$ ano, a maior demanda de mão de obra comparado aos outros sistemas devido a manutenção das espécies frutíferas. Observa-se que nos $1^{\circ}$ e $2^{\circ}$ ano, houve a manutenção do capim nas entrelinhas, o que representa 50 diárias por ano. O aumento de 60 diárias para mais de 200 diárias entre o $2^{\circ}$ e o $3^{\circ}$ ano diz respeito a inclusão das espécies anuais. Nesse modelo, dos custos totais, R\$ $112.525,11$ (64,92 \%) representam a mão de obra e R\$ 60.799,45 (35,08\%) os insumos. É importante mencionar que o agricultor possui tração animal para suas atividades. Devido a força de tração animal favorecer processos como, por exemplo, o transporte das colheitas, fez-se necessário incluir os valores de diárias deste animal. Percebeuse que, com uso da tração animal, o tempo de trabalho do agricultor diminuiu consideravelmente quando comparado com os outros resultados da mão de obra.

O SAF- 2, apresentado na Figura 3, indica uma demanda de mão de obra contínua de mais de 200 diárias entre o $1^{\circ} \mathrm{e}$ $8^{\circ}$ ano, período este dedicado principalmente ao cultivo das hortaliças. As bananeiras permanecem neste sistema até o $10^{\circ}$ ano, 
quando são retiradas completamente, o que justifica o aumento da mão de obra neste período. Por conseguinte, permanecem apenas a Laranja (Citrus spp) e o Figo (Ficus carica), o que diminui o tempo de trabalho em menos de 50 diárias por ano. Estas diárias representam principalmente o tempo de colheita, eventuais podas de condução. Neste sistema, o custo da mão de obra é de $\mathrm{R} \$ 142.220,93$ reais (64.88\%) do valor total das despesas. Já os insumos representam um custo de $\mathrm{R} \$ 76.978,80$ reais (35.12\%) no período de 15 anos.

Figura 3: Demanda de mão de obra do SAF-2.

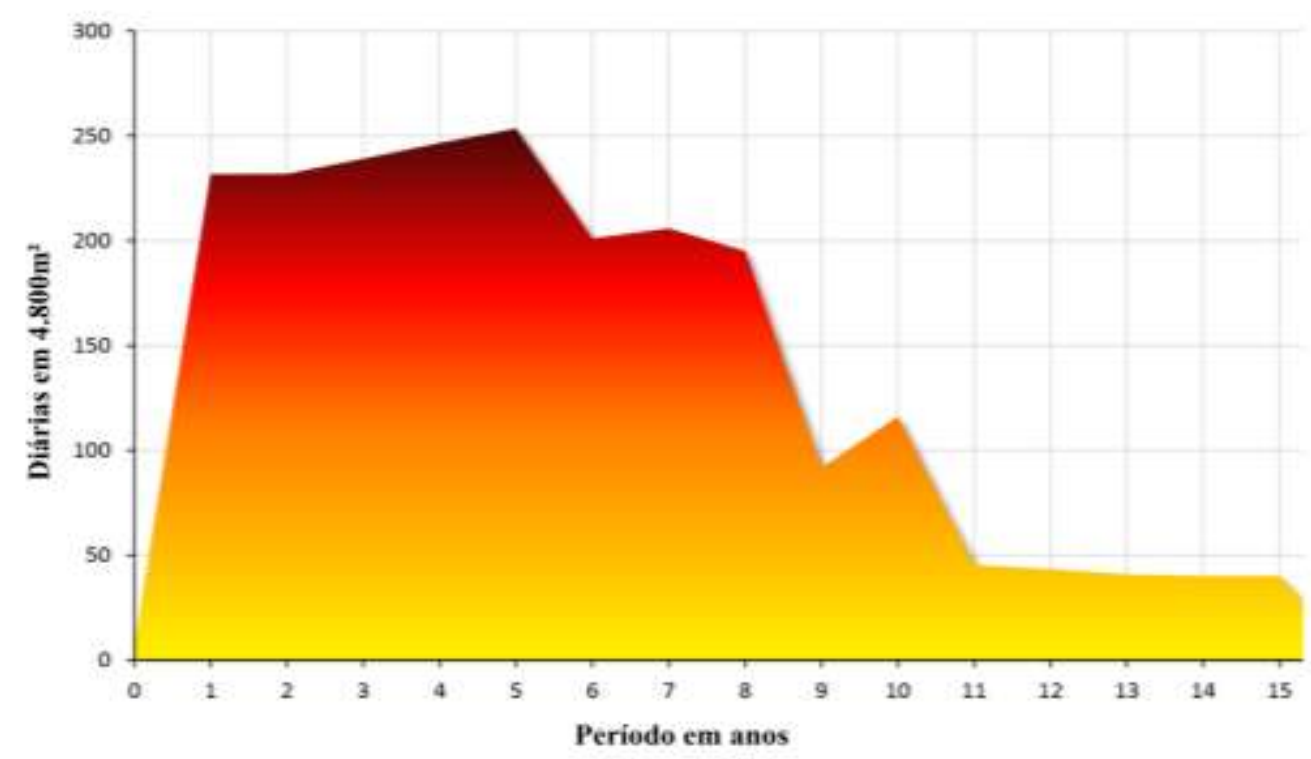

Fonte: Autores (2020).

O SAF-3, apresentado na Figura 4, foi considerado nesta pesquisa como sendo o sistema otimizado. Por ser um sistema com planejamento focado na escolha das espécies perenes adequadas, bem como diversas melhorias realizadas no desenho desse modelo, nota-se algumas diferenças nos resultados relacionados a melhoria do uso da mão de obra. Nesse modelo, o $1^{\circ}$ ano tem um pico de mão de obra relativo à implementação do SAF e ao cultivo de 40 canteiros de hortaliças, mas que não ultrapassa 300 diárias. A partir do $3^{\circ}$ ano estabiliza em 24 canteiros de espécies anuais e mantem 200 diárias até o $8^{\circ}$ ano. A partir do $9^{\circ}$ ano permanece com aproximadamente 50 diárias por ano, período este que o objetivo do sistema é a manutenção das árvores frutíferas. Nesse sistema, a mão de obra equivale a $\mathrm{R} \$ 151.426,35$ reais $(63,76 \%)$ do custo total na avaliação de um período de 15 anos. E os custos com insumos, equivalem a R \$ 86.084,27 reais (36.24\%). 
Figura 4: Demanda de mão de obra do SAF-3.

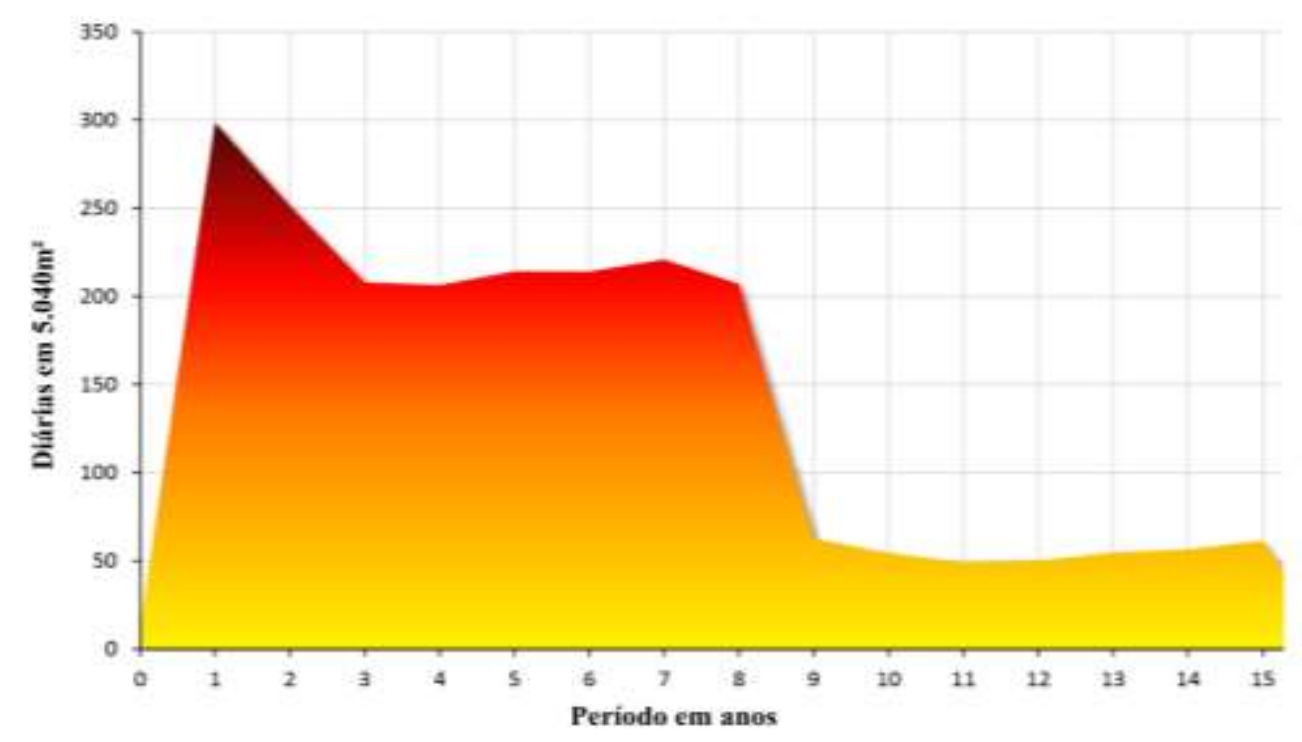

Fonte: Autores (2020).

Todos os três sistemas apontam que mais de $60 \%$ do custo refere-se a mão de obra e a partir do $9^{\circ}$ ano ocorre uma queda na demanda de mão de obra, o que representa um potencial de otimização do tempo disponível de trabalho com desenvolvimento de novas áreas. Um caminho que pode favorecer os agricultores é recomeçar os sistemas em novas áreas quando ocorrer a transição das anuais para as frutíferas. Em todos os modelos analisados, nessa fase os agricultores utilizam aproximadamente 50 diárias nos 0.5 hectares. Nessa lógica, o agricultor possui o tempo disponível para manejar até 2 hectares com espécies frutíferas e ainda manter um talhão com cultivo das espécies anuais. À medida que otimizar sua mão de obra e tiver acesso a ferramentas e tecnologias mais adequadas, poderá ampliar ainda mais sua área de SAF.

É importante mencionar ainda que, cada agricultor descrito nesta pesquisa tem um modo diferente de trabalho. A principal diferença da mão de obra que amplia ou diminui as diárias entre os três sistemas está associada a possibilidade de produzir canteiros de hortaliças conforme o espaçamento das entrelinhas (se menor ou maior que 4 metros), qualidade de luz (posição do sol ao longo do ano) e os ciclos de rotação de plantio que cada agricultor optou, ou então, tem possibilidade de cultivar. Nota-se ainda que existem poucas pesquisas e incentivos que atendam a demanda de equipamentos e ferramentas que aceleram os processos necessários para o desenvolvimento dos SAFs. Soma-se a este cenário o custo para adquirir os implementos existentes que possam facilitar a mão de obra, o que os torna muitas vezes inacessíveis para pequenos agricultores familiares. A falta de recurso financeiro ou linhas de financiamento especificas para investimento, o planejamento adequado e o acesso ao conhecimento contínuo, são fatores que influenciam na otimização da mão de obra.

\subsection{Avaliação produtiva e rentabilidade financeira: Os SAFs estão sendo efetivamente rentáveis no longo prazo?}

A análise financeira auxilia na tomada de decisão dos agricultores ao avaliar as debilidades e fortalezas dos projetos (Arco-Verde \& Amaro, 2018). Também contribui com o planejamento para melhorar a eficiência produtiva, pois é preciso compreender a importância da estabilidade produtiva dos SAFs e disponibilidade de rendimento no longo prazo. Essa perspectiva pode ser compreendida por meio do Fluxo de Caixa, conforme apresentado por Rezende e Oliveira (2013), representado pelos custos e receitas ao longo de um período. Assim como, reduzir custos com insumos contribui diretamente com o retorno financeiro do investimento. Notou-se nesta pesquisa, que o aumento do número de espécies faz crescer os custos 
diretos de mão de obra e insumos, principalmente as espécies anuais de ciclo curto. Por outro lado, a escolha correta das espécies selecionadas pode aumentar os ganhos e diminuir os custos.

No Fluxo de Caixa ajustado do SAF-1, apresentado na Figura 5, observou-se que não houve receitas nos primeiros dois anos, mas com a implantação do sistema o custo foi de $\mathrm{R} \$ 14.982,40$. Com a entrada das hortaliças a partir do $3^{\circ}$ ano, atingiu a receita máxima de $\mathrm{R} \$ 41.668,06$ no $5^{\circ}$ ano. A partir desse momento, as receitas começam a cair e se estabilizam com as espécies frutíferas. O médio e longo prazo o SAF-1 ingressa em uma fase de queda da produtividade, o que indica sua instabilidade financeira diante da necessidade de uma receita permanente do agricultor.

Já o Fluxo de Caixa do SAF-2 (Figura 5), possui uma receita no primeiro ano de R $\$ 44.761,71$ reais e suas despesas, ao considerar os custos de implantação somados com a mão de obra no cultivo das hortaliças, atingem o pico de $\mathrm{R} \$ 23.481,62$ reais. Esse modelo mantém um bom rendimento financeiro até o $5^{\circ}$ ano e com a diminuição dos canteiros de hortaliças vai decaindo até o $8^{\circ}$ ano. No momento que não cultiva mais as espécies anuais, o sistema entra em decadência, apresentando resultados de rentabilidade no $12^{\circ}$ ano $\mathrm{R} \$ 7.517,67$ reais e no $15^{\circ}$ ano $\mathrm{R} \$ 3.251,86$.

Figura 5: Fluxos de Caixa ajustados dos três SAFs analisados conjuntamente.

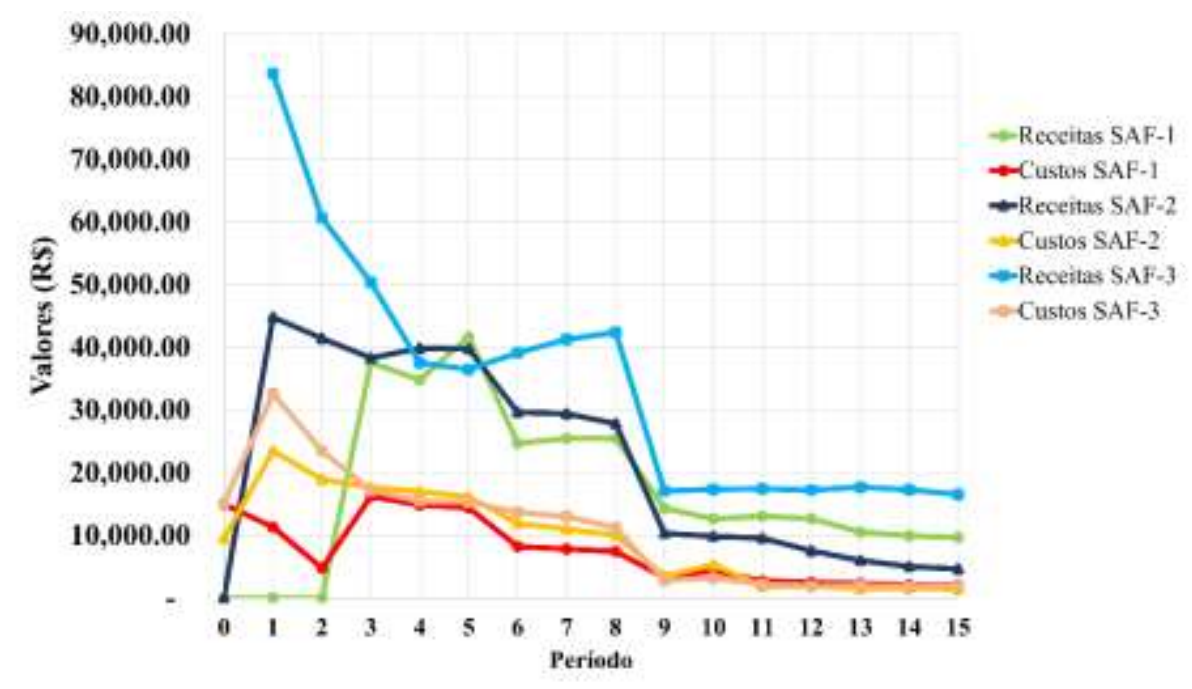

Fonte: Autores (2020).

O Fluxo de Caixa do SAF-3 (Figura 5), teve no primeiro ano uma receita de $\mathrm{R} \$ 83.684,93$ reais e o custo de $\mathrm{R} \$$ $32.589,93$ reais. A partir do $9^{\circ}$ ano o sistema estabiliza com um rendimento aproximado de $R \$ 20.000,00$, o que significa um lucro mensal em torno de $\mathrm{R} \$ 1.600,00$ reais. Essa estabilidade garante ao agricultor a possibilidade de investir em novas áreas, acessar tecnologias e ferramentas em consonância com suas necessidades e até melhorar sua qualidade de vida. 
Figura 6: SAF-2: Custos e receitas totais por produto (com rateio de custos indiretos).

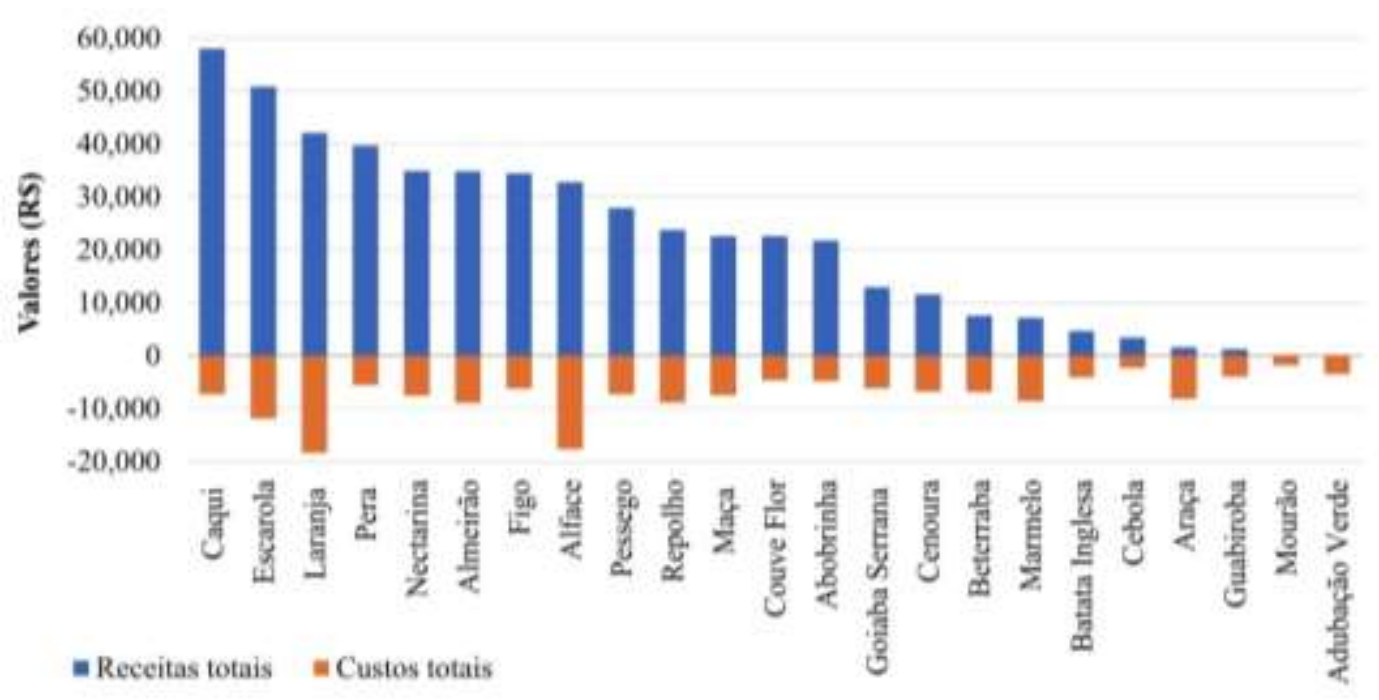

Fonte: Autores (2020).

Embora a análise individual de rendimento de determinada espécie não indique diretamente a sustentabilidade do sistema como um todo, certamente fornece uma informação útil para avaliar quais foram os ganhos e custos deste produto. Para tanto, o método indicado é se basear nos preços de compra e venda atuais do mercado (Nair, 1997; Rezende \& Oliveira, 2013). Por meio dessa análise, existe a possibilidade de tomar a decisão do quanto é válido manter esse produto no sistema ou então, substituir por outra espécie mais rentável.

Considera-se uma importante estratégia diversificar a produção de modo adequado, para proteger os agricultores familiares de eventuais quedas na produtividade devido a condições climáticas desfavoráveis e dependência das oscilações dos valores de mercado (Silva, et al., 2012). Nesse sentido, todos os modelos indicam a oportunidade de obter diferentes produtos como fontes de renda, situação essa que garante ao agricultor estabilidade de rendimento em todas as estações do ano. Esse é um dos papéis que os SAFs cumprem com facilidade, especialmente com a escolha correta das espécies perenes. Estabelecer um sistema duradouro pressupõem um projeto idealizado para produtividade no longo prazo (Palma, et al., 2020). Um projeto que dê somente margem ao cultivo de espécies anuais e sua dependência de insumos externos para adubação do solo, certamente não cumpre com um sistema bem planejamento.

O SAF- 2, apresentado na Figura 7, teve como principal receita a laranjeira (Citrus spp) e o figueira (Ficus carica). Ambas as espécies não atingiram seu potencial produtivo devido a qualidade genética e densidade da bananeira (Musa paradisíaca) nesse modelo. Observa-se que, a bananeira por sua vez, teve um elevado custo da mão de obra - pois não houve investimento de adubação para ela - e como não foi objetivo deste estudo medir os benefícios do seu uso para melhoria da qualidade do solo, compreendeu-se que sua despesa causou prejuízo para o agricultor. O Inhame (Colocasia esculenta), a Abóbora (Cucurbita spp) e o Açafrão da Terra (Curcuma longa), embora sejam espécies com reduzida mão de obra e uso de insumos, não influenciaram nas receitas. Já a Cebolinha (Allium schoenoprasum), destacou-se entre as principais receitas das espécies anuais, mas teve o maior custo de todas as hortaliças, especialmente pela sua demanda da mão de obra elevada, que está relacionada ao número de canteiros multiplicado pelo número de ciclos cultivados por ano. 
Research, Society and Development, v. 10, n. 5, e36710515163, 2021

(CC BY 4.0) | ISSN 2525-3409 | DOI: http://dx.doi.org/10.33448/rsd-v10i5.15163

Figura 7: SAF-2: Custos e receitas totais por produto (com rateio de custos indiretos).

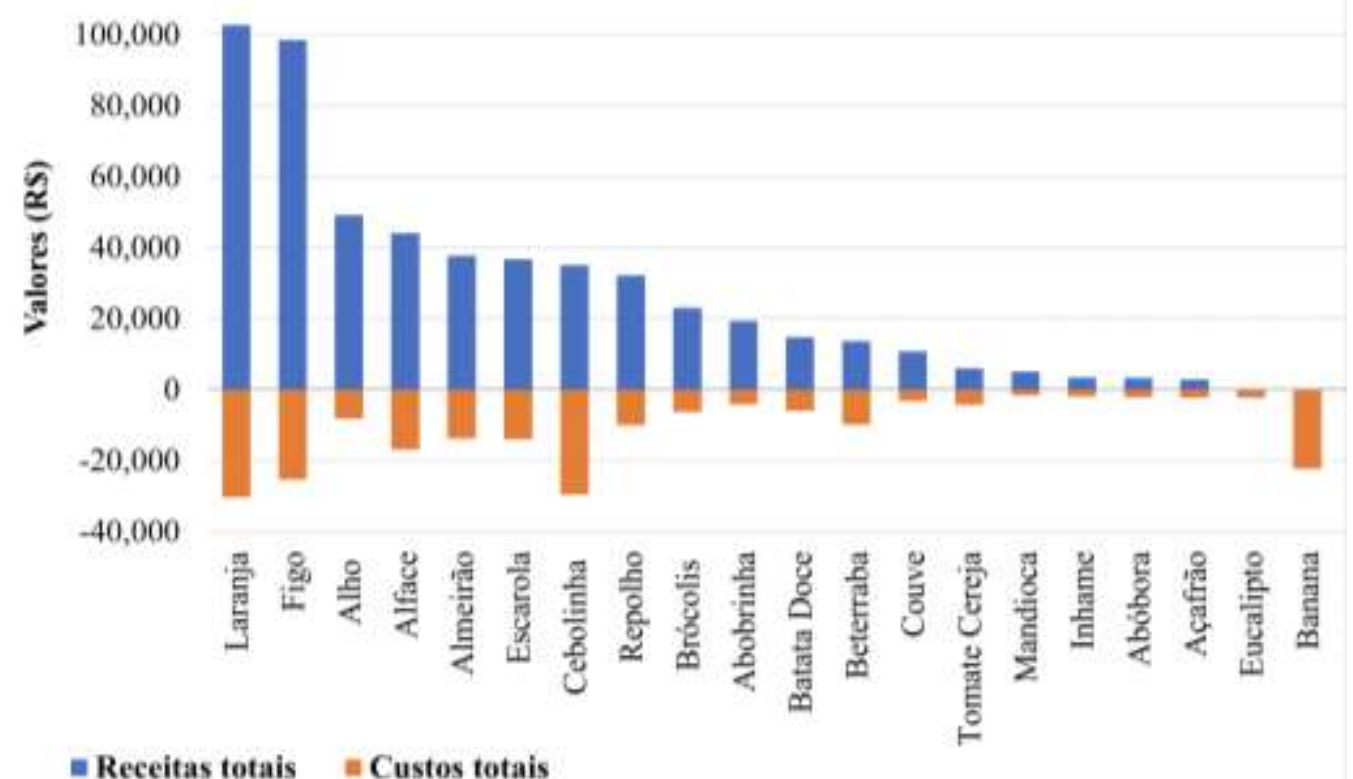

Fonte: Autores (2020).

O SAF-3, apresentado na Figura 8, corrobora com esta visão pois possui poucos indivíduos de Nogueira-Peca (Carya illinoinensis), uma árvore de ciclo produtivo que ultrapassa 100 anos, necessidade de pouca manutenção e atinge valores de mercados que variam de $\mathrm{R} \$ 20,00$ reais o $\mathrm{kg}^{-1}$ com casca e chega ao preço final de venda a mais de $\mathrm{R} \$ 80,00 \mathrm{reais}$ o $\mathrm{kg}^{-1} \mathrm{sem}$ casca. Para este estudo considerou-se o preço de venda $\mathrm{R} \$ 28,00$ reais o $\mathrm{kg}^{-1}$ com variações de queda de produtividade em alguns anos, que ocorre naturalmente em decorrência dos fatores climáticos. Outra característica é sua contribuição para ciclagem de nutrientes por ser uma árvore caducifólia, perde as folhas no inverno favorecendo um processo de 'autoadubação'.

Figura 8: SAF-3: Custos e receitas totais por produto (com rateio de custos indiretos).

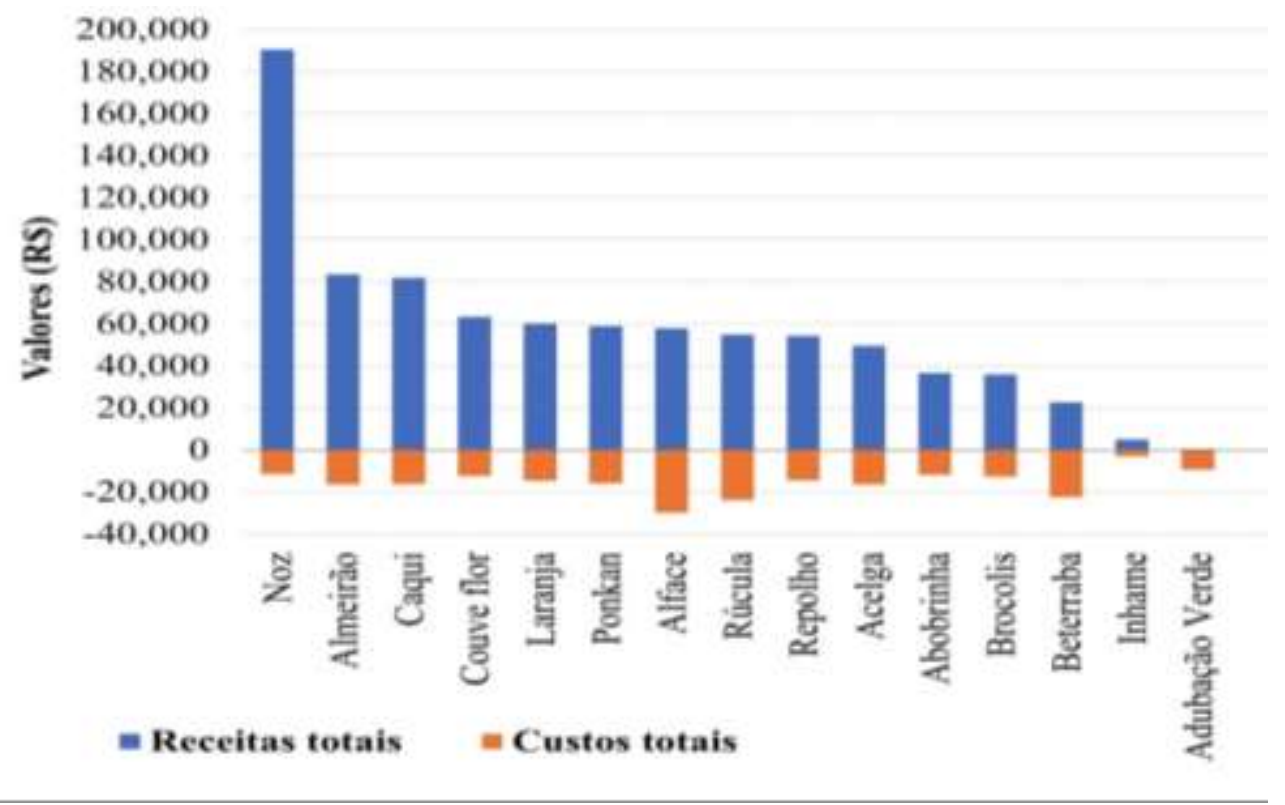

Fonte: Autores (2020). 
Por outro lado, a escolha das espécies anuais de inhame (Colocasia esculenta), e beterraba (Beta vulgaris esculenta) apresentam um resultado que pode ser considerado insatisfatório neste modelo da Figura 8. Ambas indicam um empate entre a receita e as despesas sendo necessário reconsiderar seu cultivo. Esta avaliação se torna o diferencial para melhorar o rendimento financeiro dos SAFs.

Os resultados financeiros apresentados na Tabela 3, representam a rentabilidade dos três sistemas. Por se tratar de diferentes culturas, com espécies perenes, semi-perenes e anuais, foi importante considerar o período de prognose de 15 anos para obter um resultado mais preciso de rentabilidade e assim, contribuir com as tomadas de decisão nos diferentes estágios. Para as análises desta pesquisa foram utilizados uma taxa de desconto de $8.1 \%$ a.a. (ao ano) de juros referente a taxa de desconto/juros utilizada no "Programa Nacional de Fortalecimento da Agricultura Familiar - PRONAF, já somando o seguro safra, respectivamente 4,6 e 3,5\% a.a. (ao ano). A taxa de desconto determina o valor presente dos custos ou receitas futuras, sendo o custo do uso do dinheiro atual (Arco-Verde \& Amaro, 2018; Palma, et al., 2020).

Tendo em vista que os sistemas analisados têm apenas 0.5 hectares, constatou-se que os SAFs têm singularidades muito específicas que influenciaram nos resultados de produtividade. Observa-se no Payback (Tabela 3) que o SAF-1 recuperou o investimento apenas a partir do $4^{\circ}$ ano. E os SAF-2 e SAF-3 recuperam o investimento já no primeiro ano de implantação. O SAF 3, tem o melhor desempenho produtivo e financeiro e por outro lado, possui o menor número de espécies, no total de 15, sendo considerado um sistema simplificado. Esse resultado corrobora com a importância do planejamento do sistema.

Tabela 3: Visão financeira de três SAFs no assentamento Contestado (custos receitas e despesas ajustados).

\begin{tabular}{ccccccc}
\hline Modelo & $\begin{array}{c}\text { Produtividade ton/0.5 } \\
\text { ha/ano (a) }\end{array}$ & $\begin{array}{c}\text { Receitas } \\
\mathbf{R} \$ \mathbf{h a}(\mathbf{b})\end{array}$ & $\begin{array}{c}\text { Despesas } \\
\mathbf{R} \mathbf{\$} / \mathbf{h a}(\mathbf{c})\end{array}$ & $\begin{array}{c}\text { VPL } \\
\mathbf{R} \$(\mathbf{d})\end{array}$ & $\begin{array}{c}\text { Payback } \\
\text { descontado }(\mathbf{e})\end{array}$ & $\begin{array}{c}\text { Relação } \\
(\mathbf{B} / \mathbf{C})(\mathbf{f})\end{array}$ \\
\hline SAF-1 & 12.583 & $272.344,05$ & $119.276,04$ & $153,068.01$ & 4 & 2.3 \\
\hline SAF-2 & 12.978 & $343.704,56$ & $152,661.67$ & $191,042.90$ & 1 & 2.3 \\
\hline SAF-3 & 17.533 & $511.948,70$ & $172.825,30$ & $339,123.40$ & 1 & 3.0 \\
\hline
\end{tabular}

Em que: a) A produtividade é a soma da permanência de todos os produtos, sendo quantidade e tempo de produção, já descontado as perdas e divididos por 15 anos; b) As receitas são o resultado de comercialização dos produtos; c) As despesas são a soma do valor da mão de obra em diárias, insumos diversos, materiais e ferramentas; d) Valor Presente Líquido (VPL) calcula todas as entradas e saídas, para revelar a viabilidade do investimento já descontado uma taxa de juros apropriada; e) Payback descontado indica em qual ano o investimento será recuperado; f) Relação Benefício Custo (B/C) indica se o benefício é maior que o custo. Fonte: Autores (2020).

\section{Conclusão}

Apenas um SAF apresentou a melhor estabilidade financeira, os outros dois não atingiram seu potencial produtivo e financeiro no período considerado de 15 anos. Foi constatado que as receitas geradas pelas hortaliças superaram nos primeiros anos a rentabilidade de mais de $80 \%$ das espécies perenes e que o grande desafio dos agricultores foi realizar a transição efetiva das espécies de ciclo curto para o cultivo das frutíferas. Nesse sentido, as receitas das hortaliças foram tão altas nos primeiros anos de cultivo que conseguiram manter os indicadores financeiros positivos para todo período. Observou-se também que em todos os modelos a demanda de mão de obra se concentra no cultivo das espécies de ciclo curto, atingindo mais de 200 diárias por ano. Sem as hortaliças a mão de obra reduz nesses modelos para aproximadamente 50 diárias. De fato, o sistema agroflorestal cria riqueza ao adicionar valor ao tempo de trabalho dedicado por meio da sua mão de obra. Para melhorar a produtividade e a riqueza, o agricultor deve primeiramente projetar sistemas eficazes em produzir. Em seguida, deve realizar a gestão dos sistemas de forma correta para fazer o melhor uso da sua força de trabalho, do capital investido e dos insumos utilizados. Por fim, recomenda-se para as futuras pesquisas a ênfase na análise financeira, aliado ao planejamento e a 
gestão estratégica dos sistemas agroflorestais, com objetivo de viabilizar linhas de crédito que possam incentivar sua adoção e permanência em todo Brasil.

O estudo foi aprovado pelo Comitê de Ética em Pesquisa com Seres Humanos (CEPSH) da Universidade Federal de Santa Catarina (CAAE: 86379418.6.0000.0121).

\section{Agradecimentos}

Em especial aos agricultores que sempre colaboraram de forma solicita a todas as fases à campo, ao CAPES (Coordenação de Aperfeiçoamento de Pessoa de Nível Superior), a Embrapa Florestas e ao Programa de Pós-Graduação em Agroecossistemas.

\section{Referências}

Arco-Verde, M. F. \& Amaro, J. C. (2014). Análise financeira de Sistemas Produtivos Integrados. Embrapa Florestas. 74p. Arco-Verde, M. F. \& Amaro, J. C. (2018). Análise financeira de Sistemas Agroflorestais. Embrapa Florestas. 84p. Bigarella, J. J., Blase, O. \& Brepohl, D. (1997). Lapinha: a natureza da Lapa. Lar Lapeano de Saúde.

Camargo, A., Capobianco, J. P. R. \& Oliveira, J. A. P. (2002). Meio ambiente Brasil. Avanços e obstáculos pós-Rio-92. Estação Liberdade: Instituto Socioambiental. FGV.

Caporal, F. R. \& Costabeber, J. A. (2004). Agroecologia e extensão rural: contribuições para a promoção do desenvolvimento rural sustentável. MDA/SAF/DATER: v.1.

EMATER. (2011). Plano de Recuperação de Assentamento (PRA): Projeto de Assentamento Contestado.

Ewert, M., Arco-Verde, M. F., Palma, V. H. \& Kazama, D. C. S. (2018). Planejamento e Desenvolvimento de Sistemas Agroflorestais. In: Anais Congresso Brasileiro de Sistemas Agroflorestais. Aracaju/SE.

Ewert, M. Venturieri, G. A. Steenbock, W. \& Seoane, C. E. S. (2016). Sistemas Agroflorestais Multiestrata e a legislação ambiental brasileira: desafios e soluções. Revista Meio Ambiente e Desenvolvimento. 36, 95-114.

Fernandes, G. M. \& Facco, V. A. B. (2015). Agroecologia e MST no Leste Paranaense: As experiências do Assentamento Contestado, e do Acampamento José Lutzenberger (Antonina - PR). Revista Pegada, 16, 89.

IBGE. (2017). Censo agropecuário. <https://censos.ibge.gov.br/agro/2017/templates/censo_agro/resultadosagro/index.html>.

IICA (Instituto Interamericano de Cooperação para a Agricultura). (2013). Políticas de Desenvolvimento Territorial e Enfrentamento da Pobreza Rural no Brasil. <http://repiica.iica.int/docs/B3343p/B3343p.pdf>.

Leff, E. (2011). Saber Ambiental: Sustentabilidade, Racionalidade, Complexidade, Poder. Petrópolis: Editora Vozes.496 p.

Nair, P. K. R. (1997). Directions in tropical agroforestry research: past, present, and future. Agroforestry Systems, 38(1), $223-245$.

Overbeek, W., Kröger M. \& Gerber, J. F. (2012). Um panorama das plantações industriais de árvores no Sul global. Conflitos, tendências e lutas de resistência. Relatório EJOLT (3), 108 p.

Paludo, R. \& Costabeber, J. A. (2012). Sistemas agroflorestais como estratégia de desenvolvimento rural em diferentes biomas brasileiros. Revista Brasileira de Agroecologia, 7(2).

Palma, V. H., Arco-Verde, M. F., Curcio, G. R., Mattos, L. M., Ewert. M. \& Galvão, F. (2020). Avaliação da Eficiência dos Sistemas Agroflorestais por meio de análises financeiras. Biofix Scientific Journal 5(2), 203-213.

Pereira, A. S., Shitsuka, D. M., Parreira, F. J. \& Shitsuka, R. (2018). Metodologia da pesquisa científica. UFSM. https://repositorio.ufsm.br/bitstre am/handle/1/15824/Lic_Computacao_Metodologia-Pesquisa-Cientifica.pdf?sequence=1.

Primavesi, A. (1997). Agroecologia: ecosfera, tecnosfera e agricultura. Nobel. 199 p.

Rezende, J. L. P. \& Oliveira, J. L. P. (2013). Análise econômica e social de projetos florestais. (3a ed.), 385 p.

Santos, M. J. C. \& Paiva, S. N. (2002). Os sistemas agroflorestais como alternativa econômica em pequenas propriedades rurais: estudo de caso. Ciências Florestais. 12(1), 135-141.

Santos, A. L. (2015). Agroecologia e campesinato: relativa autonomia frente ao desenvolvimento do capitalismo, um estudo de caso no assentamento contestado, Lapa-PR. Florianópolis, dissertação de Mestrado em Agroecossistemas. UFSC.

Sen, A. K. (2000). Desenvolvimento como liberdades. Companhia das Letras. 
Research, Society and Development, v. 10, n. 5, e36710515163, 2021

(CC BY 4.0) | ISSN 2525-3409 | DOI: http://dx.doi.org/10.33448/rsd-v10i5.15163

Silva, I. C. (2013). Sistemas Agroflorestais: conceitos e métodos. SBSAF. 308 p.

Silva, C. P. C., Coelho Junior, L. M., Oliveira, A. D., Scolforo, J. R. S., Rezende, J. L. P. \& Lima, I. C. G. (2012). Economic analysis of agroforestry systems with candeia. Revista Cerne, Lavras, 18(4), 585-594.

Sousa Santos, B. de S. (2009). As Vozes do Mundo. Civilização Brasileira. 672 p.

Thompson, D. \& George, B. (2009). Financial and economic evaluation of agroforestry. In: Nuberg, I. et al. Agroforestry for natural resource management. Collingwood: CSIRO Publishing, 281-330.

Wrege, M. Steinmetz, S., Reisser Junior, C. \& Almeida, I. R. de (2012). Atlas climático da região sul do Brasil. Embrapa; https://pt.climatedata.org/location/43733/.

Yin, R.K. (2015). O estudo de caso. Bookman, 5. 320 p. 